\title{
Study on Literature Representation of Zhuhai City Image
}

\author{
Ruihui $\operatorname{Han}^{1}$ \\ ${ }^{1}$ Humanities School, Jinan University, Zhuhai, Guangdong Province, China \\ Correspondence: Ruihui Han, Humanities School, Jinan University, Zhuhai, Guangdong Province, China. E-mail: \\ hanruihuihh@hotmail.com
}

Received: December 19, 2013 Accepted: January 20, 2014 Online Published: March 26, 2014

doi:10.5539/ass.v10n8p50

URL: http://dx.doi.org/10.5539/ass.v10n8p50

\begin{abstract}
This paper discusses the representation of Zhuhai as a special economic zone and famous tourist city in literature. Since Zhuhai was set up, most native writers in Zhuhai have showed narration of struggling experience in "an alien land" for Zhuhai representation. But such literary works benefit little for effectively establishing Zhuhai's positive city image and confirming its subject identity and spirit. Native writers in Zhuhai should consciously create positive and healthy social climate, shape and communicate favorable city image and enrich humanity history resources of Zhuhai so as to effectively communicate Zhuhai city image.
\end{abstract}

Keywords: literature, city image, Zhuhai, representation

The city is the converging place of human civilization. Literary works keep eternal memory for each city.

Compared with films and television works and news media, literary works are more profound for shaping city image. The communication of literary works is longer. Many famous historical cities in China such as Nanjing, Luoyang, Xi'an and Hangzhou have a large quantity of rich colorful and glorious literary works. In the history, the occurrence of these literary works makes these cities rich in profound historical deposits.

In modern times, the names of some famous writers will be connected with a city. Their writing for these cities forms unique humane scenes, such as Beijing which Lao She wrote in his works, Shanghai which Zhang Ailing wrote in her works, Nanjing which Zhu Ziqing wrote in this works and Xi'an which Jia Ping'ao wrote in his works. In their works, Hutong in Beijing, lanes in Shanghai, Qinhuai River in Nanjing and ancient storied building in Xi'an sent out strong historical atmosphere. The Hutong, lanes, Qinhuai River and ancient storied building are exactly matched with historical and humane features of these cities. Not just the city image is effectively communicated, but also the literary works are sparkling in the literature history.

Since Zhuhai Special Economic Zone was founded, literary creation in Zhuhai has been prosperous. Some famous writers appeared in Zhuhai, including Yang Xueping, Wang Hailing, Pei Bei and Deng Shan etc. Their creation have added unique scenery lines for Zhuhai, shaped city image of Zhuhai and left vivid historical memory for Zhuhai. How does Zhuhai reappear in literary works and what historical memory has been left to Zhuhai by special zone literature of Zhuhai since the reform and opening-up? These become the problems worth thinking.

\section{Effective Communication of City Literature and City Image}

Many literary works will make a place famous overnight. For example, Milan Kundera's works The Unbearable Lightness of Being made Prague become the object people long for; Chinese writer Lu Xun's Kong Yiji made "Xianheng Inn" in Wuzhen Town of Zhejiang world-famous; Shen Congwen's Border Town made western Hunan become a tourist attraction ... Literary works show city image and give materialized places with life and significance.

A British cultural research scholar Stuart Hall considers, any cultural image is a kind of construction. City image is of no exception. City image is constructed in a series of culture symbols and forms great differences with real city image, for such constructed image includes constructors' subjective thoughts and previous knowledge deposits and emotional ideas. In all culture symbol construction systems, literary works play a very important role in city construction. They add new things for a city through literary image and other means.

Compared with rural areas in literature representation, in the history, the cities reappearing in city literature were not the places for poetic dwelling, but the places full of chaos, crimes, gainful people and corruption. "In fact, 
since the moment when literature appeared in the ancient times, city literature only has occupies an unimpressive and despised position in the mind of scholars." (Zou, 2003) In particular, the awareness of valuing peasants and despising the businessmen in Chinese cultural traditions caused Chinese ancient literati always had the temperament and interest of returning to countryside, and naturally scorned cities.

Tao Yuanming's poetry Return to Countryside in China's Wei and Jin Dynasties, and Shen Congwen's western Hunan novels in modern times express praise and return to rurality. However, city image was often negative in Chinese literature, such as The Golden Lotus of Lanling Xiaoxiaosheng in Song Dynasty and Midnight of Ba Jin in modern times. Such phenomenon also appeared in western literary works. For instance, in modern times, the Irish poet Eliot's long poem Wasteland described cities as wasteland; the works of a British D.H. Lawrence in the $19^{\text {th }}$ century and Hardy also opposed modern industrial civilization and urban life, but longed for rural life. There were also Lakers in the $18^{\text {th }}$ century and the American writer Thoreau's Walden in the $20^{\text {th }}$ century. They opposed modern civilization and much yearned for natural countryside. In the works of many writers, the city became the place of evils and corruptions.

In some current literary works such as Chengdu, Please Forget me Tonight, Shenzhen, Passionate Tonight, and Chongqing, Single Man and Woman make city image negative. Compared with city literature, local literature becomes the place people remember the past times and the homeland of people's soul.

Today when urbanization course develops rapidly, such situation should be changed. China's urbanization course has gradually accelerated since 1980s. In 1990, there were 467 cities in China; in 1999, there were 668 cities, and urban population reached 230 million. (Xue, 2003) According to statistical data of Statistical yearbook for China's urban and rural construction, from 2001 to 2010, China's urban area increased to $1899921.2 \mathrm{~km}^{2}$ from $878014.97 \mathrm{~km}^{2}$, up $116.39 \%$. The annual mean growth rate was $11.64 \%$. Urban population increased by $73.41 \%$. Meanwhile, "semi-urbanization" phenomenon in China's rural areas was also very obvious. Apart from accelerated urbanization course, the proportion of Chinese peasant-workers to urban population was on the rise. Thus, cities play an increasingly important role in current world.

Cities should become the places of "poetic dwelling". It is necessary to improve urban cultural taste and popularity form the perspective of literature. However, Milan Kundera's The Unbearable Lightness of Being and Hugo's Notre Dame de Paris greatly improved the popularity of Prague and Paris so that the two cities become the places people yearn for.

\section{Zhuhai City Literature and City Image Representation}

In order to discuss literature representation of Zhuhai city image, this chapter analyzes some representative writers; works since Zhuhai became the special economic zone. Some female writers appeared in Zhuhai early, such as Yang Xueping and Wang Hailing.

Yang Xueping's "immigrant stories in the special economic zone" accurately reflected mental changes of those working and living in Zhuhai the first time.

In her creation, "immigrant stories in the special economic zone" were her important theme changes after she came to Zhuhai. Her novel Xigang reflected the experience of some female workers from inland who worked in overseas-funded factories in Zhuhai and gained the prize in the $6^{\text {th }}$ new works of new writers. Besides, her novel Stories in Rainy Season, In Zhuhai and Expecting Miracles reflected the life in the special economic zone. Immigrant experience in Zhuhai Special Economic Zone reappeared in her works through calm writing style and well-arranged plots.

Wang Hailing is also one writer reflecting living conditions of Zhuhai Special Economic Zone. Before coming to Zhuhai, she was a famous youth writer in Jiangxi. Wang Hailing was transferred to Zhuhai to work from Jiangxi in 1985. After coming to Zhuhai, her creation object and style changed. She created Dong Pu Xi Pu, Excavating the First Pot of Gold in Special Zone, Cat on the Hot Roof and Perennial Wind etc. "In Wang Hailing's works, the special zone is a place of desires. In various flaming desires, some values are burned down and some values are generated in the burning." (Huang \& Huang, 1999) Many female images appeared in Wang Hailing's special zone series of novels. The author adopted exquisite language to describe the destiny changes and mental changes of the female groups who were among the first batch workers working and living in Zhuhai.

The figures in her works are mainly classified into two types: 1) ambitious gold diggers; 2) winners in wealth. Her works narrated the stories of the first batch of gold diggers in the special zone and disclosed money and materials destroyed and distorted human nature. In her works, on the one hand, she affirmed the rationality of pursuing money and materials; on the other hand, she worried about the excessive material desire. Life track variation diagram of those immigrants due to the material desire and gold digging dream truly reappeared in the 
life of the first batch of gold diggers in the special zone described in her works.

Compared with Wang Hailing, Pei Bei is a writer really growing in Zhuhai. She once worked as a journalist, but then was engaged in literature creation. In recent years, she has been concentrating on film and TV play producing. Her works struggling in North and $4 K R A W$ gained good reputation.

$4 K R A W$ was recomposed to film in 2009. In 2010, this film and other 6 new films directed by Zhang Yimor, Jiang Wen and $\mathrm{Wu}$ Yusen were selected in the $67^{\text {th }}$ Venice International Film Festival in 2010. (Huang \& Huang, 1999) Pei Bei's medium-length novel $4 K R A W$ describes individual options in the world full of material desires with humorous style, reveals the blundering psychology of measuring all with money and satirized showy and vain living conditions.

In the novel, the protagonist Dushi wants to make big money through the way which he believes that can works well. The topic of the novel is money, and the plot barely makes the readers associate with Zhuhai, especially with the history and culture of Zhuhai. If the novel can make people associate with Zhuhai, the only matter it makes people conjour up is that Zhuhai is a city which full of the tragedies and comedies about money. The topic is very common in literature, but the readers cannot find any features of Zhuhai. The novel is narrated through the perspective of a non-native. The world it unfolds before people's eyes is alien.

Most of the writers in Zhuhai describe Zhuhai in such style. The result is caused by the following factors. First, the main part of Zhuhai population is formed by migrants from other provinces. The native people of Zhuhai is very few compared to the migrants. Second, Zhuhai is deemed as an economic special zone, but not a place full of historic sites. Although Zhuhai is a tourist city, it is because of the beautiful nature scenes it has but not the historic sites. When the writers depict Zhuhai, they would naturally associate Zhuhai with economic special zone and the beautiful nature scenes. Third, as an administrative city, Zhuhai is a city which was set up in 1979, so in this sense Zhuhai has very short history. In ancient time, the place of Zhuhai was forbidden zone because of the confrontation between Chinese government and pirates etc. So the culture could not flourish in such place. Compared to Hangzhou and Nanjing etc., which have much historic culture, Zhuhai is a city which has little historic culture.

But in modern times, there were lots of celebrities born in Zhuhai, and Zhuhai is a very important point of junction between China and west. The place witnessed the great change of China. There are lots of stories can be told about Zhuhai of modern times.

In recent years, Zhuhai government tries to find the historic culture so as to enhance the competition strength of the city. So the works which present the historic culture are valued. But it is a pity that such works are very few for the above reasons.

In the later period, the main representative of Zhuhai writer creation group is Deng Shan.

Deng Shan is also an immigrant in Zhuhai. In recent years, his works have obtained many prizes. Thus, he is called a bright new star in Zhuhai cultural circle. Dead Island and Alive Island he created in 1995 won the award of excellent works for "new writers" at Chinese Writers and Literature Center. His short story Gurongwan gained the first place in "literary and spiritual civilization" works contest of People's Daily monthly magazine. Moreover, his works Sunny Days in Hong Kong, Zhuhai's Children, Boiling Liquor with Lotus and Sea Gull gained awards. In 1996, his lyric Zhuhai Stat was written to music and was selected in the teaching material of the primary schools in Guangdong Province.

Compared with the previous writers, Deng Shan's works stress active shaping of Zhuhai city image. He hopes there are many works making the history and culture of Zhuhai reappear. Deng Shan's works not just involve the life of immigrants in Zhuhai, but also contain local features and history of Zhuhai. His novel Dead Island and Alive Island takes Guishan Island of Zhuhai as the prototype and describes inner world of new and old generations. Meanwhile, the history and current situations of Guishan Island of Zhuhai reappear. His works highly praise the historical theme of the reform and opening-up and positively eulogize the struggling course of people in Zhuhai constructing the homeland. Thus, his works are filled with idealism color and have positive education significance.

In Deng Shan's works, the culture and social changes of Zhuhai in recent years especially the time after the reform and opening-up of China are important content. He depicts the change of mentality of the native after the reform and opening-up. But because of the deficiency of historic culture in Zhuhai, his works do not represent the ancient culture of Zhuhai.

But in all of the writers in Zhuhai, Deng Shan is a writer who has self-consciousness to represent the culture of Zhuhai. In his works, the readers would learn about the native culture of Zhuhai, but not only the stories of 
immigrants. "Zhuhai provides me infinite source of creative writing. My career is in Zhuhai and my life is also in Zhuhai," (Mu, 1998) Deng Shan said.

In representative works of most of Zhuhai writers, business stories of immigrant strugglers reappear in most works. In these works, Zhuhai is described as a painful or happy place due to material desires. Only a few writers such as Deng Shan truly reflect regional features and historical culture of Zhuhai.

The deficiency of the representation of Zhuhai native culture in Zhuhai modern literature works is because of the lack of ancient native culture of Zhuhai on the one hand, but on the other hand, it is because of the lack of self-consciousness to represent the Zhuhai native culture and the motive to expose the positive side of Zhuhai. So what most readers find in such works are the desire and money, and they cannot get the understanding of Zhuhai as a cultural existence.

\section{Defects of Zhuhai City Literature for City Representation}

As a newly-developing city, Zhuhai city image urgently needs effective and positive communication. The traditional historical culture needs to be deepened in literary works so as to establish the theme identity of the city. However, such creation effect cannot be seen in the plentiful works. This current situation needs changing. What is interesting is that the phenomenon is very common in China.

Currently, Chinese city literary creation has much one-sided narration. Some critics criticize this. "Like city feeling of Wei Hui and Mianmian full of flesh awareness, although 'violence, grace, eroticism, joy, riddle, machine, power, death and human truth' and 'ill omen, conspiracy, ulcer, dagger, lust, poison, insaneness and moonlight' are complete and deduce 'urban living state' vividly, if such works are regarded as the whole of 'city literature', if is far away from true cities." (Xia, 2011) Obviously, many city literary works neglect the inherent features of the city and fail to pay attention to explanation of historical connotation and humanistic color of the city.

In Four Aesthetic Lectures, Li Zehou classified aesthetical standards into three levels: "pleasant to ears and eyes", "pleasant to heart" and "pleasant to spirit". Many city novels only stay at the level of "pleasant to ears and eyes", pursue sensory stimulation and express hedonism. Thus, it is hard to make literary creation own long-lasting vitality.

Through analysis of the problems in China's city literary creation, it can be found that many literary works highlight individual survival and pursuit and stress human material desire, but neglect expression of loftier state and sense of social responsibility. Individualization is one of features of modern social development. "Individual living interest is consumed or delayed in various uncertain materialized world full of lures until completely indulged in all kinds of virtual life styles which are open in form, but closed in reality so that individuality is completely closed in real life and people loose themselves ..." (Zou, 2007)

Literary creation will always be influenced by atmosphere of times. Some literary works in Zhuhai cannot get rid of such interference. Individual self-assertion and ability exertion accord with the features of times-stressing independence of character. However, overemphasizing individuals and excessively individual rights and interests as well as material desire make the narration own too many lonely images. This goes against advocating positive and healthy atmosphere of times. It is required to put literature in historical traditions and make it connected with traditional culture so as to own wider and more profound expressive force and communicate more positive spirit.

Zhuhai is not just a tourist city with beautiful scenery, but also possesses profound humanity history deposits. Of course, Zhuhai's humanity history deposits were formed in modern times. Deficiency of ancient historic culture does not mean the lack of culture in Zhuhai. The culture created in modern times is significant. If the literature works represent the characters of the city effectively, the city would get more popularity, and the competition strength of it would be improved.

But recent literary works are often workplace novels or the literature based on the theme of rural migrants. In such works, people cannot find Zhuhai, they only read the stories which can take place in anywhere else of China or even the world.

"Novel creation in Zhuhai blooms. It is pity that the novels describing Zhuhai are rare." "If the novels do not involve Zhuhai from the content to the form, from the theme to materials, people in other provinces and cities will not admit it is 'Zhuhai literature' even if they are published on periodicals and we consider they belong to Zhuhai literature with tolerant mentality, for the background is unrelated to Zhuhai and cannot carry forward cultural spirit of people in Zhuhai. The literature of writers in Zhuhai and Zhuhai literature are two different things. The writers owning Zhuhai household register can be regarded as Zhuhai writers, but if the form and core of their novels do not involve Zhuhai, other will not admit it is Zhuhai literature no matter how we stress it." 
(Deng, 2011) the writer Deng Shan said so. Deng Shan is one of the rare writers who have the self-consciousness to depict Zhuhai's culture and characters.

In the history, plentiful literary narrations have effective communication effect for regions. But since Zhuhai Special Economic Zone was set up, literary creation in Zhuhai have failed to effectively reflect Zhuhai city culture and show historical cultural features of Zhuhai. This has no benefit for Zhuhai city competition and is to the disadvantage of development of Zhuhai. Such current situation needs to be effectively changed.

\section{References}

Deng, S. (2011). We Have Something to Speak on Zhuhai Literature. Zhuhai Media, (2), 25.

Huang, Y., \& Huang, J. (1999). Brief Comment on the Economic Special Zone Series of Wang Hailing. Journal of Hanshan Normal University, (1), 98-102.

$\mathrm{Mu}$, Z. (1998). The Writer Loving Sea, Reading Sea and Writing Sea: Sketch on Deng Shan. The Novel Series of Celestial Phenomena beside the Sea. Guangzhou: Flower City Publishing House. 284.

Xia, J. (2011). The Urban Literature Should Expose the Spirit Form of the City. Exploration and Discussion, (4), 16-17.

Xue, X. (2003). How to Develop the Urban Moderation? Economy Daily, B2.

Zhang, Y. (2010). The Homegrown Film of Zhuhai Selected for Venice Film Festival: The Film 4K RAW Which Is Directed by Authoress Pei Pei of Our City and the Famous Directress Ning Ying. Zhuhai Daily, B3.

Zou, H. (2003). Paradise? Wasteland? Exploration of the New Period Urban Literature. Journal of Chongqing Polytechnic College, (3), 134-136.

Zou, S. (2007). Condition of Materialization of Modern Period Spiritual Life and the Critique on It. Chinese Social Sciences, (5), 54-63.

\section{Copyrights}

Copyright for this article is retained by the author(s), with first publication rights granted to the journal.

This is an open-access article distributed under the terms and conditions of the Creative Commons Attribution license (http://creativecommons.org/licenses/by/3.0/). 